\title{
The effects of a 2-h trial of high-flow oxygen by nasal cannula versus Venturi mask in immunocompromised patients with hypoxemic acute respiratory failure: a multicenter randomized trial
}

Virginie Lemiale ${ }^{1 *}$, Djamel Mokart ${ }^{2}$, Julien Mayaux ${ }^{3}$, Jérôme Lambert ${ }^{4}$, Antoine Rabbat ${ }^{5}$, Alexandre Demoule ${ }^{3}$ and Elie Azoulay ${ }^{1}$

\begin{abstract}
Introduction: In immunocompromised patients, acute respiratory failure (ARF) is associated with high mortality, particularly when invasive mechanical ventilation (IMV) is required. In patients with severe hypoxemia, high-flow nasal oxygen (HFNO) therapy has been used as an alternative to delivery of oxygen via a Venturi mask. Our objective in the present study was to compare HFNO and Venturi mask oxygen in immunocompromised patients with ARF.

Methods: We conducted a multicenter, parallel-group randomized controlled trial in four intensive care units. Inclusion criteria were hypoxemic ARF and immunosuppression, defined as at least one of the following: solid or hematological malignancy, steroid or other immunosuppressant drug therapy, and HIV infection. Exclusion criteria were hypercapnia, previous IMV, and immediate need for IMV or noninvasive ventilation (NIV). Patients were randomized to $2 \mathrm{~h}$ of HFNO or Venturi mask oxygen.

Results: The primary endpoint was a need for IMV or NIV during the 2-h oxygen therapy period. Secondary endpoints were comfort, dyspnea, and thirst, as assessed hourly using a 0-10 visual analogue scale. We randomized 100 consecutive patients, including 84 with malignancies, to HFNO $(n=52)$ or Venturi mask oxygen $(n=48)$. During the 2-h study treatment period, 12 patients required IMV or NIV, and we found no significant difference between the two groups ( $15 \%$ with HFNO and $8 \%$ with the Venturi mask, $P=0.36$ ). None of the secondary endpoints differed significantly between the two groups.
\end{abstract}

Conclusions: In immunocompromised patients with hypoxemic ARF, a 2-h trial with HFNO improved neither mechanical ventilatory assistance nor patient comfort compared with oxygen delivered via a Venturi mask. However, the study was underpowered because of the low event rate and the one-sided hypothesis.

Trial registration: ClinicalTrials.gov identifier: NCT02424773. Registered 20 April 2015.

\footnotetext{
* Correspondence: virginie.lemiale@aphp.fr

${ }^{1}$ Medical ICU, Saint Louis Teaching Hospital, AP-HP, 1 avenue Claude

Vellefaux, 75010 Paris, France

Full list of author information is available at the end of the article
}

C Biomed Central

(c) 2015 Lemiale et al. Open Access This article is distributed under the terms of the Creative Commons Attribution 4.0 International License (http://creativecommons.org/licenses/by/4.0/), which permits unrestricted use, distribution, and reproduction in any medium, provided you give appropriate credit to the original author(s) and the source, provide a link to the Creative Commons license, and indicate if changes were made. The Creative Commons Public Domain Dedication waiver (http://creativecommons.org/publicdomain/zero/1.0/) applies to the data made available in this article, unless otherwise stated. 


\section{Introduction}

Acute respiratory failure (ARF) remains the most common and severe life-threatening complication in immunocompromised patients [1-3]. Hypoxemic ARF can be related to a variety of causes $[4,5]$, which must be identified by etiological investigations conducted simultaneously with symptomatic management. Many immunocompromised patients with ARF require ventilatory support within a few hours after admission to the intensive care unit (ICU) [6-8]. Avoiding invasive mechanical ventilation (IMV) significantly decreases the risk of death $[1,3]$. Thus, choosing the optimal device for delivering oxygen is of the utmost importance to decrease the IMV rate while maintaining safe levels of oxygenation and ensuring patient comfort.

Noninvasive ventilation (NIV) has been reported to decrease mortality in immunocompromised patients with hypoxemic ARF [9]. However, NIV had smaller benefits in the most recent studies, chiefly because of a sharp drop in mortality among patients given IMV [10-13]. Moreover, NIV failure was associated with high mortality $[14,15]$ and with patient discomfort and anxiety [16].

High-flow nasal oxygen (HFNO) therapy was first introduced to treat children [17, 18], but it is now increasingly used in adults managed in emergency departments or ICUs [19-22]. This method consists of delivering a high flow of humidified oxygen through a large nasal cannula (HFNC). It not only delivers a high fraction of inspired oxygen $\left(\mathrm{FiO}_{2}\right)$ but also generates some measure of positive pressure [23], ensures washout of the nasopharyngeal dead space [23, 24], and diminishes the work of breathing [25].

Few studies in adults have compared HFNO with oxygen delivered through a facemask. Most of them were small, uncontrolled, and used physiologic parameters as the primary endpoints. They showed improvements in oxygen saturation, partial pressure of arterial oxygen $\left(\mathrm{PaO}_{2}\right)$, patient comfort, respiratory rate, and dyspnea $[19,21,26,27]$. None compared intubation rates between the two oxygen delivery methods. A retrospective, uncontrolled study of 45 immunocompromised patients treated with HFNO found a $66 \%$ intubation rate [28].

In the present study, our objective was to compare HFNO with oxygen delivered through a Venturi mask in immunocompromised patients admitted to the ICU with ARF. We conducted a multicenter randomized controlled trial with the primary endpoint of need for NIV or IMV within the first $2 \mathrm{~h}$ of oxygen therapy.

\section{Methods}

\section{Overview}

We performed an open, prospective, multicenter, parallel-group randomized controlled trial in four ICUs between November 2012 and April 2014. The appropriate ethics committee approved the research protocol
(Comité de protection des personnes Ile de France IX, 12 November 2011, RCB 2011-A00241-40). Informed nonopposition consent was obtained from all patients before study inclusion. The funding source (Fisher \& Paykel Healthcare, Auckland, NZ) provided the nasal cannulas for HFNO and funds for insurance but had no other role in the study.

\section{Patients}

Consecutive immunocompromised patients admitted to the ICU for ARF were screened for inclusion. ARF was defined as onset of respiratory symptoms within $72 \mathrm{~h}$ before ICU admission and either a need for oxygen greater than $6 \mathrm{~L} / \mathrm{min}$ to maintain peripheral capillary oxygen saturation $\left(\mathrm{SpO}_{2}\right)$ above $95 \%$ or symptoms of respiratory distress (tachypnea $>30 / \mathrm{min}$, intercostal recession, labored breathing, and/or dyspnea at rest). In addition to ICU admission for ARF, inclusion criteria were age over 18 years and immunosuppression (solid or hematological malignancy, solid organ transplant, longterm or high-dose [ $\geq 1 \mathrm{mg} / \mathrm{kg} /$ day] steroid therapy, other immunosuppressive treatment, or HIV infection). Exclusion criteria were hypercapnia $(>45 \mathrm{mmHg}$ ), mechanical ventilation before ICU admission, need for immediate NIV or IMV, and patient refusal to participate in the study. Patients who met all inclusion criteria and none of the exclusion criteria were allocated at random in a 1:1 ratio, with stratification on study center, to HFNO or oxygen delivery via a Venturi mask with the use of a permuted block method. Opaque, sealed envelopes ensured identity concealment. The physician who included the patient opened the sealed envelope and started the oxygen device of the randomized group. The nature of the study treatments precluded blinding.

\section{Study treatments}

Oxygen therapy was started immediately after inclusion. In the Venturi mask group, $\mathrm{FiO}_{2}$ was $60 \%(15 \mathrm{~L} / \mathrm{min})$ initially and was then adjusted as needed to maintain $\mathrm{SpO}_{2}$ of at least $95 \%$. Humidification was not applied. In the HFNO group, HFNO was used with heated humidified circuit, and initial flow was $40-50 \mathrm{~L} / \mathrm{min}$ with an $\mathrm{FiO}_{2}$ of $100 \%$ and was then adjusted as needed to maintain $\mathrm{SpO}_{2}$ of at least $95 \%$. Respiratory deterioration in immunocompromised patients with ARF occurs within the first few hours after ICU admission; we therefore confined the study to the first $2 \mathrm{~h}$ of HFNO or Venturi mask oxygen delivery. No crossover between the two treatments was allowed during this time window.

\section{Data collection}

The data were collected prospectively. The Simplified Acute Physiology Score II (SAPS II) was computed within $24 \mathrm{~h}$ of ICU admission, and the Sequential Organ 
Failure Assessment (SOFA) score was recorded at inclusion $[29,30]$. At randomization and after 60 and $120 \mathrm{mi}-$ nutes of study treatment, we recorded the respiratory rate, heart rate, arterial blood pressure, $\mathrm{SpO}_{2}$, and $\mathrm{FiO}_{2}$. At the same time points, the patients completed three visual analogue scales (VASs; $0-10$ scoring) on which 0 indicated absence and 10 the highest possible levels of dyspnea, discomfort, and thirst, respectively. The cause of ARF was established on the basis of predefined criteria [6]. We recorded the need for NIV and/or throughout the ICU stay and the ICU length of stay.

\section{Endpoints}

The primary endpoint was the need for IMV or NIV during or at the end of the 2-h study period. IMV or NIV was started in patients who met at least one of the following criteria: worsening respiratory distress, defined as $\mathrm{SpO}_{2}$ less than $92 \%$, respiratory rate more than 40 breaths/min or labored breathing, regardless of the oxygen flow rate; inability to maintain $\mathrm{PaO}_{2}$ greater than $65 \mathrm{mmHg}$ with $\mathrm{FiO}_{2}$ greater than 0.6; and hemodynamic or neurologic deterioration. The choice between NIV and IMV was at the physician's discretion.

Secondary endpoints were the VAS scores for comfort, thirst, and dyspnea; respiratory rate; and heart rate.

\section{Statistical analysis}

The sample size calculation was based on superiority of the HFNC strategy. On the basis of an earlier study [31], we expected oxygenation failure rates of $30 \%$ in the Venturi mask group and $10 \%$ in the HFNC group at the end of the 2-h trial. A sample size of 49 in each group would have a power of $80 \%$ to detect such a difference (with a one-sided $\alpha$ of 0.05). The total number of patients included was rounded up to 100 .

All analyses regarding the primary outcome were performed on the basis of the intention-to-treat principle. We compared the proportion of patients with a primary endpoint (including analyses of the separate components, NIV or intubation and IMV) between the two strategies and tested for significance using Fisher's exact test. Because the observed effect was in the opposite direction, the tests were two-sided to ensure the possibility of assessing the statistically significant superiority of the Venturi mask strategy. Secondary continuous endpoints (comfort, thirst, dyspnea, heart rate, and respiratory rate) were compared between the two strategies among patients still receiving the planned treatment at the end of the 2-h trial using the Wilcoxon rank-sum test. All statistical analyses were performed using R software (version 2.13.1).

\section{Results}

Figure 1 is the patient flowchart. Of 550 consecutive immunocompromised patients admitted to the 4 participating ICUs, 102 met our selection criteria and were randomized: 53 to the HFNO group and 49 to the Venturi mask group. In each group, one patient withdrew consent. Thus, the final analysis included 100 patients: 52 in the HFNO group and 48 in the Venturi mask group.

\section{Patient characteristics}

We report the baseline patient characteristics in Table 1. The most common causes of immunosuppression were steroid or immunosuppressant treatment $(n=65)$ and hematological malignancies $(n=61)$, and $15 \%$ of patients had more than one cause of immunosuppression. At ICU admission, the patients had tachypnea (respiratory rate, 27 [22-32] breaths $/ \mathrm{min}$ ) and $\mathrm{SpO}_{2}$ of $96 \%$ [94-98\%] under 12 [6-12] L/min of oxygen through a standard oxygen mask, a SOFA score of 3 [2-5], and an SAPS II of 39 [30-51]. The primary cause of ARF was related to sepsis for 50 patients (Table 1).

None of the patients received oxygen through a Venturi mask, HFNO, or NIV before randomization, which occurred on day $0[0-1]$ after ICU admission. Before randomization, oxygen was provided through oxygen prong, oxygen bagless mask, or oxygen bag mask. At baseline, the VAS scores were 3 [2-5] for discomfort, 5 [2-7] for dyspnea, and 6 [4-8] for thirst (Table 2 and Fig. 2).

\section{Study endpoints}

Of the 100 patients, 88 received the randomly allocated oxygen treatment throughout the 2 -h period and 12 required NIV or IMV before the end of the 2-h period. There was no significant difference between the HFNO and Venturi mask groups regarding the need for IMV/ NIV during the 2-h study period (Table 2).

None of the secondary endpoints differed significantly between the Venturi mask and HFNO groups (Table 2 and Figs. 2 and 3). Moreover, we did not find an interaction between etiology of ARF (sepsis vs. no sepsis) and efficacy of oxygen device $(P=0.44)$.

\section{Subsequent outcomes}

IMV was required within 1 day after randomization in three additional patients: one in the HFNO group and two in the Venturi mask group. Throughout their ICU stay, a total of 39 patients required IMV. In patients who required intubation after the end of the study period, IMV occurred within 1 [0-2] day. Oxygen was required for 5 [2-8] days. ICU length of stay was 7 [3-13] days, and ICU mortality was $24 \%$.

\section{Discussion}

In this randomized trial in immunocompromised patients with ARF, mechanical ventilation requirements within the first $2 \mathrm{~h}$ showed no significant difference between HFNO and oxygen delivered via a Venturi 


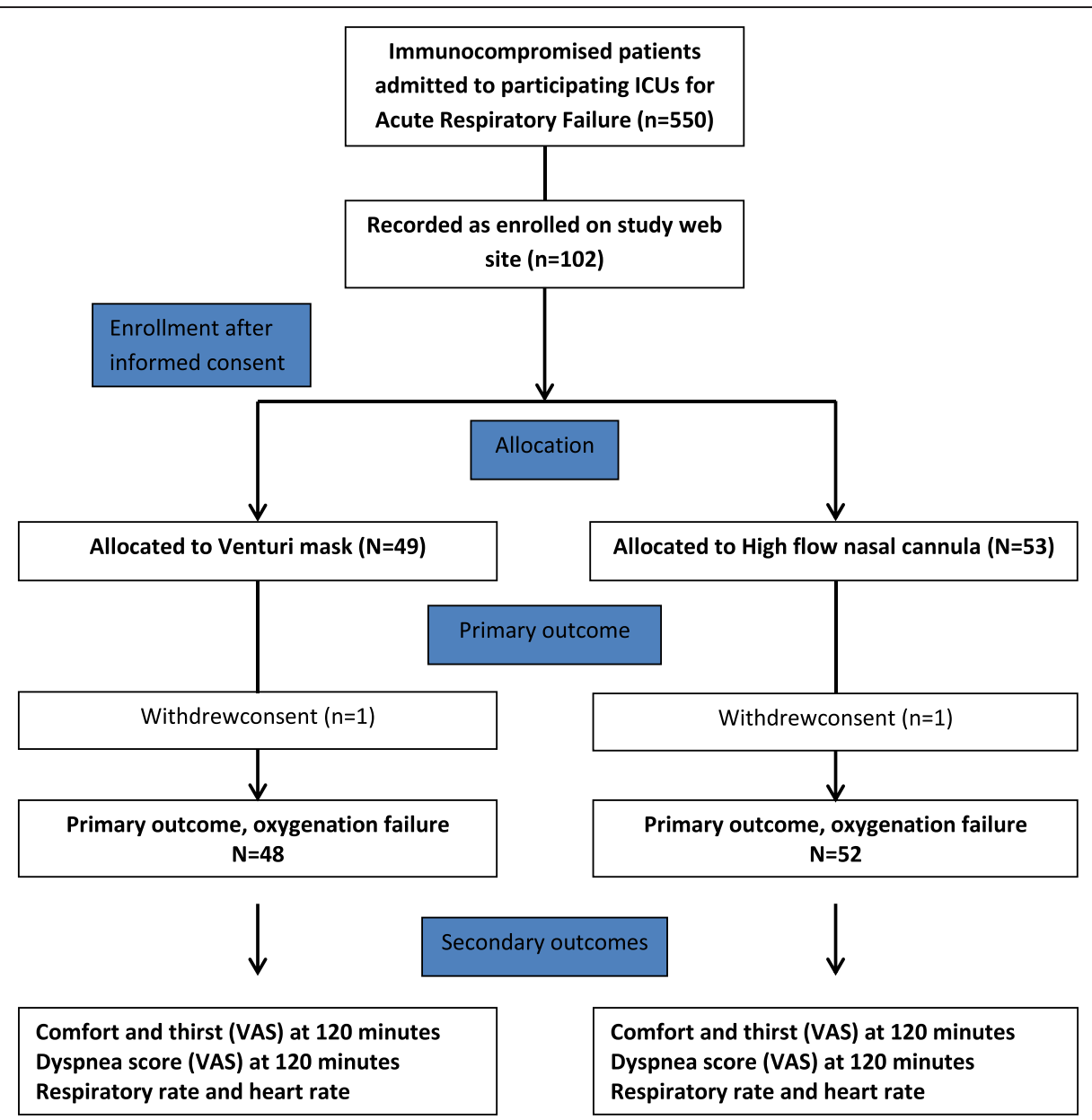

Fig. 1 Patient flowchart. HFNO high-flow nasal oxygen, ICU intensive care unit, IMV invasive mechanical ventilation, NIV noninvasive ventilation, VAS visual analogue scale

mask. In keeping with this finding, no differences were found for respiratory rate, dyspnea score, or heart rate. Finally, patient comfort was not different between the two treatments.

A randomized trial with a final crossover period compared HFNO with standard nonhumidified oxygen therapy in 37 consecutive ICU patients with ARF who did not require immediate NIV or MIV [32]. Dryness and discomfort were significantly lower in the HFNO group. The patients were not immunocompromised, and they had less severe hypoxemia compared with those in our study. In a trial conducted in a cardiothoracic and vascular ICU, researchers randomized 60 patients to HFNO or heated and humidified oxygen therapy via a standard facemask [31]. The need for IMV or NIV within $24 \mathrm{~h}$ was lower in the HFNO group $(10.3 \%$ vs. $30 \%, P=$ 0.006). Neither comfort nor dyspnea was assessed. Moreover, most of the patients had undergone heart surgery and were therefore likely to benefit from the positive expiratory pressure delivered by HFNO [31]. Our patients had severe hypoxemia and immune deficiencies. In a randomized trial with 310 patients with hypoxemic ARF, the intubation rate was lower with HFNO than with NIV or standard oxygen in the subgroup with the most severe hypoxemia at baseline $\left(\mathrm{PaO}_{2} / \mathrm{FiO}_{2}\right.$ ratio $\left.\leq 200\right)$, but not in the overall population [33]. In the FLORALI study, $26 \%$ of patients were immunocompromised. Among patients with ARF, those with hematological malignancies more often require NIV or IMV than other patients do [22, 31]. Thus, of 45 patients with hematological malignancies who received HFNO for ARF, 30 (66 \%) required IMV [28].

The failure of HFNO to decrease the need for mechanical ventilatory assistance in our study may be ascribable to several factors. The underlying disease associated with immune deficiency (e.g., malignancy, transplantation, or systemic inflammatory disease) may have been a source of patient discomfort that was not influenced by the mode of oxygen delivery. Second, the time needed to improve oxygenation during ARF may be longer in immunocompromised patients than in other patients [34]. Thus, a longer trial would perhaps have provided different results. However, 
Table 1 Patient characteristics at randomization

\begin{tabular}{|c|c|c|}
\hline Variables & $\begin{array}{l}\text { HFNO group } \\
(n=52)\end{array}$ & $\begin{array}{l}\text { Venturi mask group } \\
(\mathrm{n}=48)\end{array}$ \\
\hline Age, yr, median [25th-75th percentile] & $59.3[43-70]$ & $64.5[53.25-72]$ \\
\hline Males, n (\%) & $38(73.1)$ & $32(66.7)$ \\
\hline \multicolumn{3}{|l|}{ Comorbidities, n (\%) } \\
\hline Chronic respiratory failure & $7(13.5)$ & $4(8.3)$ \\
\hline Chronic kidney failure & $2(3.8)$ & $3(6.2)$ \\
\hline Chronic heart failure & $4(7.7)$ & $2(4.2)$ \\
\hline \multicolumn{3}{|l|}{ Cause of immunosuppression, $\mathrm{n}(\%)$} \\
\hline Solid malignancy & $15(28.8)$ & $8(16.7)$ \\
\hline Hematological malignancy & $31(59.6)$ & $30(62.5)$ \\
\hline HIV infection & $3(5.8)$ & $5(10.4)$ \\
\hline Steroid treatment & $13(25.0)$ & $15(31.2)$ \\
\hline Other immunosuppressant drugs & $23(44.2)$ & $14(29.2)$ \\
\hline \multicolumn{3}{|l|}{ Final etiology of $A R F, b(\%)$} \\
\hline Sepsis & $25(48.1)$ & $25(52.0)$ \\
\hline Cardiogenic pulmonary edema & $5(9.6)$ & $2(4.1)$ \\
\hline Noninfectious pulmonary disease & $5(6.8)$ & $7(14.5)$ \\
\hline Lung involvement by the underlying disease & $7(13.4)$ & $9(18.7)$ \\
\hline Large pleural effusion & $0(0)$ & $1(2.0)$ \\
\hline Pneumocystis pneumonia & $5(9.6)$ & $2(4.1)$ \\
\hline Miscellaneous $^{c}$ & $3(5.7)$ & $1(2.0)$ \\
\hline No diagnosis & $2(3.8 \%)$ & $1(2.0)$ \\
\hline SAPS II at ICU admission, median [25th-75th percentile] & $42[29.5-52]$ & $37.5[31.5-46.5]$ \\
\hline SOFA score at randomization, median [25th-75th percentile] & $3.5[2-6]$ & $3[2-5]$ \\
\hline Days since respiratory symptom onset & $3[2-8]$ & $3[2-7.25]$ \\
\hline \multicolumn{3}{|l|}{ Clinical status at randomization } \\
\hline Respiratory rate, breaths/min, median [25th-75th percentile] & $26[21.7-31.2]$ & $27[22-32.2]$ \\
\hline $\mathrm{SpO}_{2}, \%$, median [25th-75th percentile] & 96 [94-98] & 96 [95-98.2] \\
\hline Estimated $\mathrm{PaO}_{2} / \mathrm{FiO}_{2}$ ratio at admission & $128[48-178]$ & $100[40-156]$ \\
\hline Mean arterial pressure, $\mathrm{mmHg}$, median [25th-75th percentile] & $86.8[82.2-95.3]$ & $80[74-89.3]$ \\
\hline Normal Glasgow Coma Scale score, n (\%) & $49(94.2)$ & $48(100)$ \\
\hline Confusion, n (\%) & $4(7.7)$ & $1(2.1)$ \\
\hline
\end{tabular}

HFNO high-flow nasal oxygen, ARF acute respiratory failure, ICU intensive care unit, SAPS /I Simplified Acute Physiology Score II (range 0-163 points, with worse scores indicating greater disease severity), SOFA Sequential Organ Failure Assessment, $\mathrm{SpO}_{2}$ peripheral capillary oxygen saturation, $\mathrm{PaO}_{2} / \mathrm{FiO}_{2}$ ratio of partial pressure of arterial oxygen to fraction of inspired oxygen

${ }^{a}$ The groups were compared using the $x^{2}$ test for qualitative variables and the Wilcoxon test for quantitative variables.

${ }^{b}$ More than one etiology could be suspected at admission.

cPulmonary embolism, lung metastasis, neutropenia recovery, extrapulmonary acute respiratory distress syndrome, drug-related pulmonary toxicity

respiratory deterioration in patients with malignancies has been reported to occur chiefly within a few hours of ARF onset [6]. Third, although researchers in most studies of HFNO in adults used a $40 \mathrm{~L} / \mathrm{min}$ oxygen flow $[19,22,23]$, as in our trial, there is some evidence that higher flows may improve comfort by increasing air humidification $[25,35]$. Investigators in a crossover study compared HFNO, oxygen via a Venturi mask, and continuous positive airway pressure in ten ICU patients immediately after tracheostomy removal [23]. Each device was tested with three oxygen flow rates $(15,30$, and $45 \mathrm{~L} / \mathrm{min})$. However, in that study as in our study, HFNO did not improve patient comfort compared with the Venturi mask. Fourth, in our 2-h study, NIV was not administered before randomization. In a randomized trial of postextubation HFNO versus standard care in 340 heart surgery patients, although the oxygenation failure rate was 
Table 2 Primary and secondary endpoints in the two treatment groups

\begin{tabular}{lll}
\hline & $\begin{array}{l}\text { HFNO group } \\
(\mathrm{n}=52)\end{array}$ & $\begin{array}{l}\text { Venturi mask group } \\
(\mathrm{n}=48)\end{array}$ \\
\hline Primary endpoint & & \\
Number (\%) of patients requiring mechanical ventilation & $8(15 \%)$ & $4(8 \%)$ \\
$\quad$ Noninvasive mechanical ventilation & $6^{\mathrm{a}}$ & $3^{\mathrm{a}}$ \\
$\quad$ Invasive mechanical ventilation & 4 & 2 \\
Secondary endpoints, median [25th-75th percentile] & & $3[0-5]$ \\
Discomfort VAS score ${ }^{\mathrm{b}}$ at 120 min & $3[1-5]$ & $3[1-6]$ \\
Dyspnea VAS score ${ }^{\mathrm{b}}$ at 120 min & $3[2-6]$ & $6[5-9]$ \\
Thirst VAS score ${ }^{\mathrm{b}}$ at 120 min & $6[3-8]$ & $25[21-31]$ \\
Respiratory rate at 120 min, breaths/min & $25[22-29]$ & $99[83-112]$ \\
Heart rate at 120 min, beats/min & $98[90-110]$ & 0.36 \\
\hline
\end{tabular}

HFNO high-flow nasal oxygen, VAS visual analogue scale

${ }^{a}$ Two patients in the HFNO group and one patient in the Venturi mask group received noninvasive ventilation followed by invasive mechanical ventilation

${ }^{\mathrm{b}}$ All three VASs ranged from 0 (absence of discomfort, dyspnea, or thirst) to 10 (worst possible discomfort, dyspnea, or thirst)

higher with standard care, comfort scores were lower with HFNO [36].

The present study has several limitations. We did not use a crossover design. However, ARF can worsen quickly in immunocompromised patients, confounding the assessment of patient comfort, and we therefore limited the study period to $2 \mathrm{~h}$ [37]. HFNO patients remained on HFNO throughout the 2-h study. Second, sources of discomfort were not assessed. Discomfort can be due to dyspnea, HFNO-related noise, nasal obstruction, or sources unrelated to ARF or its treatment. In a previous study, HFNO compared with a standard oxygen mask did not significantly diminish nasal obstruction but did improve comfort by decreasing dryness [32]. Moreover, in a recent study, airway dryness was different in the two groups after $24 \mathrm{~h}$. A longer study would allow different results. A new HFNO device that is less noisy has been developed but was not evaluated in our study.

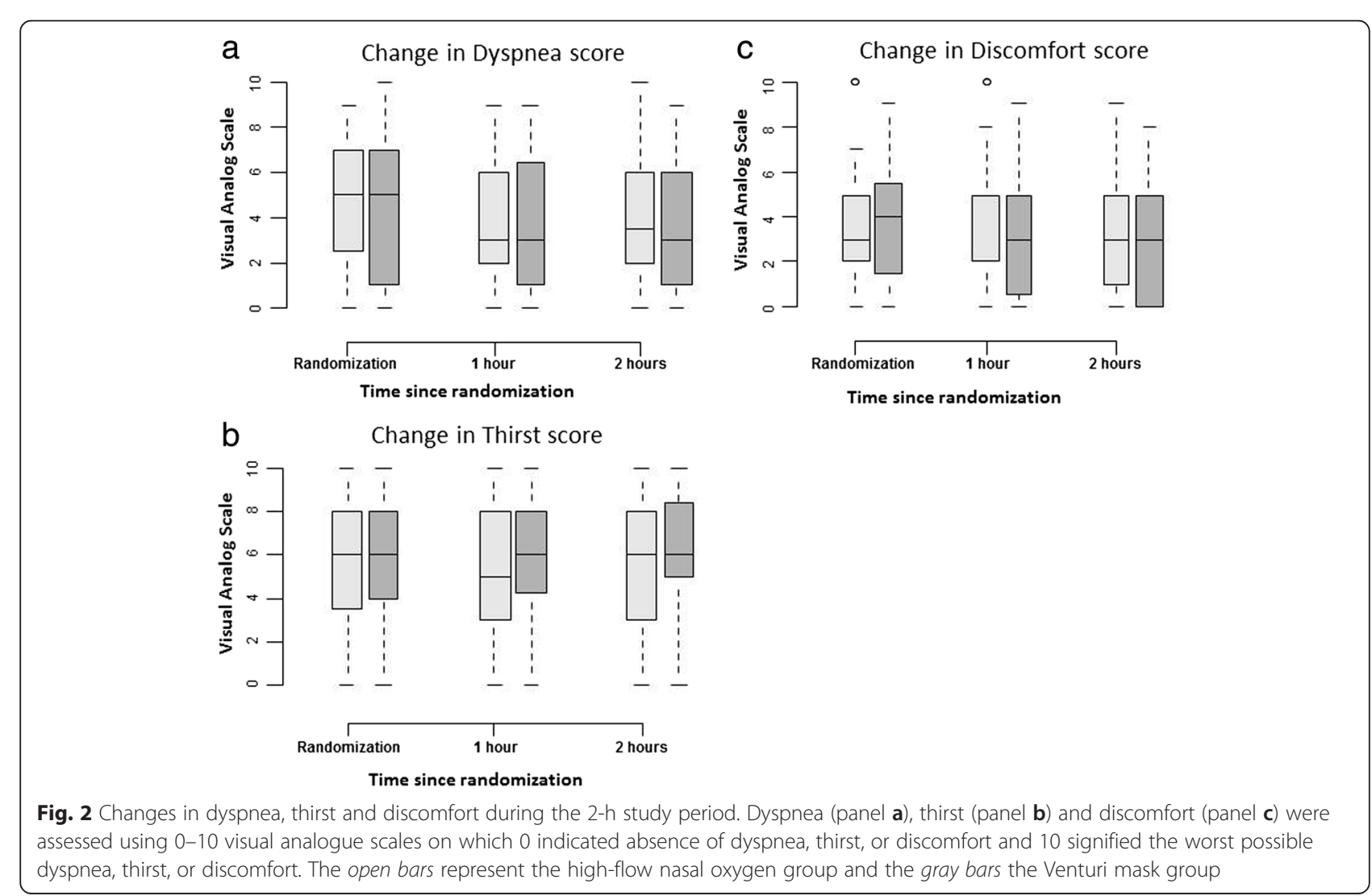



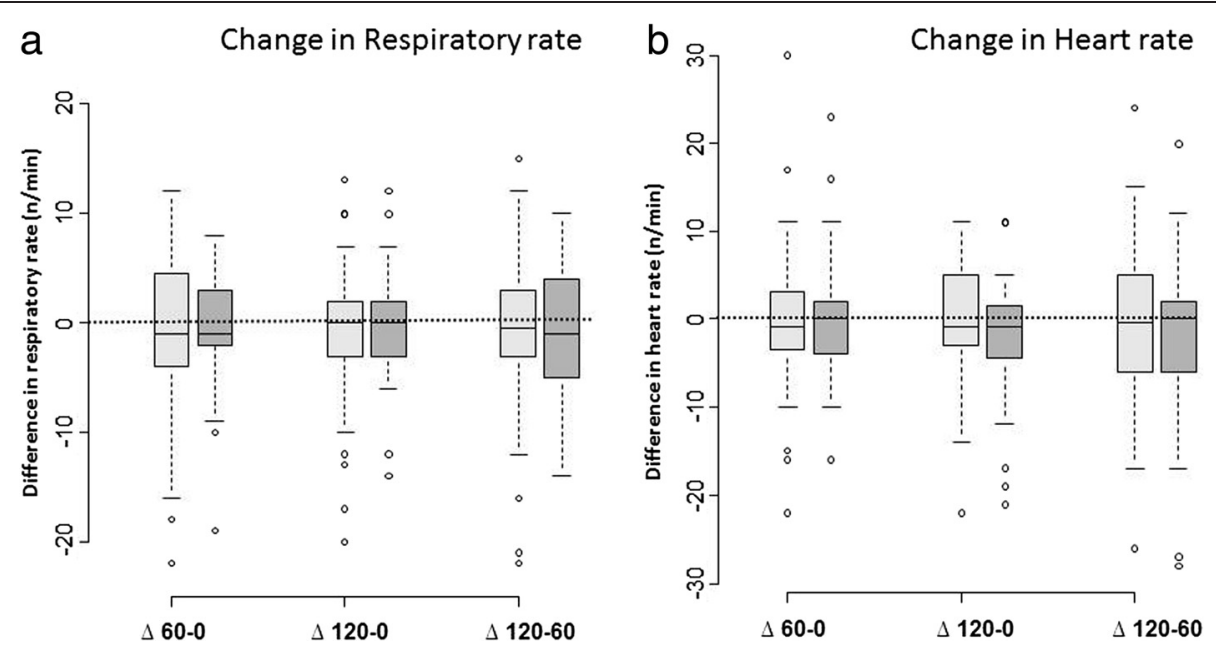

Fig. 3 Respiratory rate (panel a) and heart rate (panel b) changes during the 2-h study period. The open bars represent the high-flow nasal oxygen group and the gray bars the Venturi mask group. $\Delta 60-0$ indicates the difference between randomization and the 1-h time point. $\Delta 120-60$ indicates the difference between the 1-h and 2-h time points. $\Delta 120-0$ indicates the difference between randomization and the 2-h time point

Third, the low frequency of HFNO failure precluded a statistical assessment of factors independently associated with IMV or NIV. Identifying such factors would be of interest, as prolonged HFNO therapy might worsen outcomes by delaying mechanical ventilation [37, 38]. Fourth, the statistical power of our study was lower than planned, as the oxygen failure rate in the Venturi mask group was $8 \%$ instead of the expected $25 \%$. Moreover, the study was initially designed to demonstrate superiority of HFNC using a one-sided test; thus, it was clearly underpowered to demonstrate the inferiority of HFNC compared with the Venturi facial oxygen mask. At the time the study protocol was developed, the number of patients needed was assessed on the basis of Parke et al.'s study, which was the only published study in which intubation rate was compared between the two devices. In the Parke et al. 's study, HFNO failure was assessed within $24 \mathrm{~h}$ in cardiovascular patients. However, ARF in immunocompromised patients could worsen faster and intubation could occur earlier than in cardiovascular patients. For this reason, we did not perform a crossover study. Within the short duration of our study, we recorded a low failure rate. Patients intubated after the study period required IMV within 1 [0-2] day. A longer study period would produce different results. Moreover, patients were admitted and included in the study very early, without any other organ failure, but they were severely hypoxemic and $39 \%$ of them were ultimately intubated.

\section{Conclusions}

In immunocompromised patients with ARF, $2 \mathrm{~h}$ of HFNO neither decreased the need for mechanical ventilation nor improved patient comfort. However, the study was underpowered because of the low event rate and one-sided hypothesis. Studies aimed at identifying the sources of discomfort and targets for improvement are needed, as are longer trials of HFNO in immunocompromised patients with ARF.

\section{Key messages}

- In immunocompromised patients admitted to the ICU with acute respiratory failure, the need for noninvasive or invasive mechanical ventilation within the first $2 \mathrm{~h}$ was not significantly different between the group given high-flow nasal oxygen therapy and the group given oxygen via a Venturi mask.

- No differences were found between the two groups with regard to patient comfort, dyspnea, respiratory rate, or heart rate.

\section{Abbreviations}

ARF: Acute respiratory failure; $\mathrm{FiO}_{2}$ : Fraction of inspired oxygen; HFNC: High-flow nasal cannula; HFNO: High-flow nasal oxygen; ICU: Intensive care unit; IMV: Invasive mechanical ventilation; NIV: Noninvasive ventilation; $\mathrm{PaO}_{2}$ : Partial pressure of arterial oxygen; SAPS: Simplified Acute Physiology Score; SOFA: Sequential Organ Failure Assessment; $\mathrm{SpO}_{2}$ : Peripheral capillary oxygen saturation; VAS: Visual analogue scale.

\section{Competing interests}

VL was funded by Fisher \& Paykel to present the results at the ESICM meeting in Paris. The other authors declare that they have no competing interests.

Authors' contributions

$V L, M D, J M, A R$, JL, and EA contributed substantially to study conception and design. $V L, M D, J M$, and $A R$ contributed to data acquisition $V L, J L$, and $E A$ contributed to data analysis and interpretation. VL drafted the article. VL, MD, $J M, A R, A D$, and EA critically revised the manuscript for important intellectual content. All authors read and approved the final manuscript. 


\section{Acknowledgments}

Fisher \& Paykel provided the oxygen delivery devices and provided the funds needed for study insurance and presentation of the results at the ESICM meeting. Fisher \& Paykel had no role in designing or conducting the study; collecting, analyzing, or interpreting the data; writing the manuscript; or deciding to submit the manuscript for publication.

\section{Author details}

${ }^{1}$ Medical ICU, Saint Louis Teaching Hospital, AP-HP, 1 avenue Claude Vellefaux, 75010 Paris, France. ${ }^{2}$ Medical-Surgical ICU, Institut Paoli Calmettes, 13000 Marseilles, France. ${ }^{3}$ Biostatistics Department, Saint Louis Teaching Hospital, AP-HP, Paris, France. ${ }^{4}$ Respiratory ICU, Pitié Salpétrière Teaching Hospital, AP-HP, Paris, France. ${ }^{5}$ Respiratory ICU, Cochin Teaching Hospital, AP-HP, Paris, France.

Received: 30 June 2015 Accepted: 10 October 2015

Published online: 02 November 2015

\section{References}

1. Azevedo LC, Caruso P, Silva UV, Torelly AP, Silva E, Rezende E, et al. Outcomes for patients with cancer admitted to the ICU requiring ventilatory support: results from a prospective multicenter study. Chest. 2014;146:257-66.

2. Azoulay E, Lemiale V, Mokart D, Pène F, Kouatchet A, Perez P, et al. Acute respiratory distress syndrome in patients with malignancies. Intensive Care Med. 2014:40:1106-14.

3. Azoulay E, Mokart D, Pène F, Lambert J, Kouatchet A, Mayaux J, et al Outcomes of critically ill patients with hematologic malignancies: prospective multicenter data from France and Belgium - a Groupe de Recherche Respiratoire en Reanimation Onco-Hématologique study. J Clin Oncol. 2013;31:2810-8.

4. Azoulay E, Thiéry G, Chevret S, Moreau D, Darmon M, Bergeron A, et al. The prognosis of acute respiratory failure in critically ill cancer patients. Medicine (Baltimore). 2004;83(6):360-70

5. Canet E, Osman D, Lambert J, Guitton C, Heng AE, Argaud L, et al. Acute respiratory failure in kidney transplant recipients: a multicenter study. Crit Care. 2011:15:R91.

6. Azoulay E, Mokart D, Lambert J, Lemiale V, Rabbat A, Kouatchet A, et al. Diagnostic strategy for hematology and oncology patients with acute respiratory failure: randomized controlled trial. Am J Respir Crit Care Med. 2010;182(8):1038-46.

7. Azoulay E, Mokart D, Rabbat A, Pène F, Kouatchet A, Bruneel F, et al. Diagnostic bronchoscopy in hematology and oncology patients with acute respiratory failure: prospective multicenter data. Crit Care Med. 2008;36:100-7.

8. Azoulay E, Schlemmer B. Diagnostic strategy in cancer patients with acute respiratory failure. Intensive Care Med. 2006:32:808-22.

9. Hilbert G, Gruson D, Vargas F, Valentino R, Gbikpi-Benissan G, Dupon M, et al. Noninvasive ventilation in immunosuppressed patients with pulmonary infiltrates, fever, and acute respiratory failure. N Engl J Med. 2001;344:481-7.

10. Benoit DD, Soares M, Azoulay E. Has survival increased in cancer patients admitted to the ICU? We are not sure. Intensive Care Med. 2014;40:1576-9.

11. Lemiale V, Lambert J, Canet E, Mokart D, Pène F, Rabbat A, et al. Identifying cancer patients with acute respiratory failure at high risk for intubation and mechanical ventilation. Respir Care. 2014;59:1517-23.

12. Mokart D, Pastores SM, Darmon M. Has survival increased in cancer patients admitted to the ICU? Yes. Intensive Care Med. 2014;40:1570-2.

13. Pène F, Salluh Jl, Staudinger T. Has survival increased in cancer patients admitted to the ICU? No. Intensive Care Med. 2014;40:1573-5.

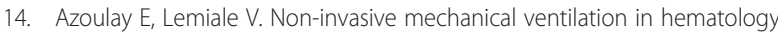
patients with hypoxemic acute respiratory failure: a false belief? Bone Marrow Transplant. 2012:47:469-72.

15. Gristina GR, Antonelli M, Conti G, Ciarlone A, Rogante S, Rossi C, et al. Noninvasive versus invasive ventilation for acute respiratory failure in patients with hematologic malignancies: a 5-year multicenter observational survey. Crit Care Med. 2011;39:2232-9.

16. Azoulay E, Kouatchet A, Jaber S, Lambert J, Meziani F, Schmidt M, et al. Noninvasive mechanical ventilation in patients having declined tracheal intubation. Intensive Care Med. 2013;39:292-301.

17. Manley BJ, Owen LS, Davis PG. High-flow nasal cannulae in very preterm infants after extubation. N Engl J Med. 2014;370:385-6.
18. Woodhead DD, Lambert DK, Clark JM, Christensen RD. Comparing two methods of delivering high-flow gas therapy by nasal cannula following endotracheal extubation: a prospective, randomized, masked, crossover trial. J Perinatol. 2006;26:481-5.

19. Lenglet H, Sztrymf B, Leroy C, Brun P, Dreyfuss D, Ricard JD. Humidified high flow nasal oxygen during respiratory failure in the emergency department: feasibility and efficacy. Respir Care. 2012;57:1873-8.

20. Parke RL, Eastwood GM, McGuinness SP, the George Institute for Global Health and the Australian and New Zealand Intensive Care Society Clinical Trials Group. Oxygen therapy in non-intubated adult intensive care patients: a point prevalence study. Crit Care Resusc. 2013;15:287-93.

21. Roca O, Riera J, Torres F, Masclans JR. High-flow oxygen therapy in acute respiratory failure. Respir Care. 2010;55:408-13.

22. Sztrymf B, Messika J, Mayot T, Lenglet H, Dreyfuss D, Ricard JD. Impact of high-flow nasal cannula oxygen therapy on intensive care unit patients with acute respiratory failure: a prospective observational study. J Crit Care. 2012;27:324.e9-13.

23. Chanques G, Riboulet F, Molinari N, Carr J, Jung B, Prades A, et al. Comparison of three high flow oxygen therapy delivery devices: a clinical physiological cross-over study. Minerva Anestesiol. 2013;79:1344-55.

24. Dewan NA, Bell CW. Effect of low flow and high flow oxygen delivery on exercise tolerance and sensation of dyspnea: a study comparing the transtracheal catheter and nasal prongs. Chest. 1994;105:1061-5.

25. Chikata Y, Izawa M, Okuda N, Itagaki T, Nakataki E, Onodera M, et al. Humidification performances of two high flow nasal cannula devices: a bench study. Respir Care. 2013;58:1442-8.

26. Corley A, Caruana LR, Barnett AG, Tronstad O, Fraser JF. Oxygen delivery through high-flow nasal cannulae increase end-expiratory lung volume and reduce respiratory rate in post-cardiac surgical patients. Br J Anaesth. 2011;107:998-1004.

27. Sztrymf B, Messika J, Bertrand F, Hurel D, Leon R, Dreyfuss D, et al. Beneficial effects of humidified high flow nasal oxygen in critical care patients: a prospective pilot study. Intensive Care Med. 2011;37:1780-6.

28. Lee HY, Rhee CK, Lee JW. Feasibility of high-flow nasal cannula oxygen therapy for acute respiratory failure in patients with hematologic malignancies: a retrospective single-center study. J Crit Care. 2015;30:773-7.

29. Le Gall JR, Lemeshow S, Saulnier F. A new Simplified Acute Physiology Score (SAPS II) based on a European/North American multicenter study. JAMA. 1993;270:2957-63.

30. Vincent JL, Moreno R, Takala J, Willatts S, De Mendonça A, Bruining H, et al. The SOFA (Sepsis-related Organ Failure Assessment) score to describe organ dysfunction/failure: on behalf of the Working Group on Sepsis-Related Problems of the European Society of Intensive Care Medicine. Intensive Care Med. 1996;22:707-10.

31. Parke RL, McGuinness SP, Eccleston ML. A preliminary randomized controlled trial to assess effectiveness of nasal high-flow oxygen in intensive care patients. Respir Care. 2011;56:265-70.

32. Cuquemelle E, Pham T, Papon JF, Louis B, Danin PE, Brochard L. Heated and humidified high-flow oxygen therapy reduces discomfort during hypoxemic respiratory failure. Respir Care. 2012;57:1571-7.

33. Frat JP, Thille AW, Mercat A, Girault C, Ragot S, Perbet S, et al. High-flow oxygen through nasal cannula in acute hypoxemic respiratory failure. $\mathrm{N}$ Engl J Med. 2015;372:2185-96.

34. Mayaud C, Cadranel J. A persistent challenge: the diagnosis of respiratory disease in the non-AIDS immunocompromised host. Thorax. 2000;55:511-7.

35. Parke RL, Eccleston ML, McGuinness SP. The effects of flow on airway pressure during nasal high-flow oxygen therapy. Respir Care. 2011;56:1151-5.

36. Parke R, McGuinness S, Dixon R, Jull A. Open-label, phase II study of routine high-flow nasal oxygen therapy in cardiac surgical patients. Br J Anaesth. 2013;111:925-31.

37. Mokart D, Azoulay E, Schnell D, Bourmaud A, Kouatchet A, Pène F, et al. Acute respiratory failure in neutropenic patients is associated with a high post-ICU mortality. Minerva Anestesiol. 2013;79:1156-63.

38. Kang BJ, Koh Y, Lim CM, Huh JW, Baek S, Han M, et al. Failure of high-flow nasal cannula therapy may delay intubation and increase mortality. Intensive Care Med. 2015:41:623-32. 